Karstenia 42: 33-38, 2002

\title{
Alciphila vulgaris, a new genus and species of Deuteromycetes
}

\author{
HARRI HARMAJA
}

\begin{abstract}
HARMAJA, H. 2002: Alciphila vulgaris, a new genus and species of Deuteromycetes. - Karstenia 42: 33-38. Helsinki. ISSN 0453-3402.

The new form genus Alciphila Harmaja (Hyphomycetes) is described. It is characterized by $(i)$ a superficial mycelium composed of voluminous hyaline hyphae, (ii) conidium development terminally in unspecialized hyphal ends, and (iii) large elongated brown aleurioconidia which possess a thick, complex wall with longitudinal ridges and a hyaline perisporium. The type and only species of the new genus is Alciphila vulgaris Harmaja which is described as a new species at the same time. Judged from qualitative studies in the field and the herbarium, $A$. vulgaris occurs in a special ecological niche: on forest litter and mosses which have been impregnated by the urine of European elk (Alces alces L.), accompanied by some species of the Pezizales (Ascomycetes). The species is reported from several localities in Finland and one in Norway. The interesting ecological niche concerned, a spot which has received elk urine, is discussed briefly.
\end{abstract}

Key words: ammonia fungi, Byssonectria, conidia, elk urine, Finland, Hyphomycetes, metapopulation, Peziza, Pezizales, Pseudombrophila

Harri Harmaja, Botanical Museum, Finnish Museum of Natural History, P.O. Box 47, FIN-00014 University of Helsinki, Finland www.helsinki.fi/people/harri.harmaja/

\section{Introduction}

Old fruit bodies of fleshy fungi, animal dung, and dead bodies of animals are known as the principal ecological niches of many specialized species belonging especially to fungi of different groups, insects, in some cases even mosses and algae. The habitats mentioned provide the organism especially with a rich supply of nitrogen. These niches are sharply delimited in space and rather sharply in time; the populations living in the niches can be described as subpopulations which constitute a metapopulation.

Sagara (e.g. 1975; Sagara \& al. 1993) created the term ammonia fungi for fungal species that, exclusively or preferably, grow in habitats with a rich supply of ammonia (occurrences directly in dung or dead bodies excluded). He has treated forest with urea but also discovered and studied spontaneous niches: $(i)$ places on the ground close to dung of animals, (ii) places contaminated with human urine/and or feces (either buried in the soil or not), (iii) underground nests of mice, voles and other mammalia (with a latrine or not), (iv) places close to dead bodies of mammalia (either buried or not), and even ( $v$ ) an old wasp nest. Sagara (1975) also supposed that places where animals had directly urinated could be a habitat for these fungi but he was not familiar, either personally or through literature, with any large animal species with urine enough to produce the effect. However, in NW Europe, for instance, such an animal exists and it has locally large populations: the spots in nature where an elk (Alces alces L.) has urinated, have been known interesting mycologically for some time (e.g., Eckblad 1968, Harmaja 1979, 1986). The network formed by these curious niches can be compared to the metapopulations formed by organism populations in fungal fruit bodies, dung heaps, and dead bodies of animals mentioned above, but the species composition and espe- 
cially the ecology and population dynamics of the urine spots have been studied very fragmentarily.

The elks of, e.g., southern Finland are known to spend the wintertime very often in somewhat elevated places of the terrain, especially if covered with young pine forest. Apparently, the animals urinate during the winter a good amount on the more or less frozen earth surface through the snow cover. The considerable amount of urine released by these big animals at a time falls into a small area and subsequently often gets frozen. Due to the cold period of the year, the urine (and the compounds that are converted from it) remain for a fairly long time in the same place for the advantage of the microbes! Sagara (1975) found that the supply of aqueous ammonia is the main factor to explain the characteristic fungal composition in his experimental plots. In NW Europe, towards the spring, the elk urine on the soil surface is hydrated with water from melting snow resulting in aqueous ammonia ("ammonium hydroxide, $\left.\mathrm{NH}_{4} \mathrm{OH}^{\prime \prime}\right)$; the $\mathrm{pH}$ of the substrate rises at the same time.

In macroscopical appearance, these urinated spots reach from a few square centimetres to some square decimetres, have thin or thick mycelium (called 'subiculum' in some cases), and usually contain apothecia of cup-fungi. The spots are mostly found very close to the dung heaps, or at least where signs of the staying of elks are obvious. Some observations would suggest that this kind of fertilization is generally somewhat harmful for vascular plants, mosses and lichens.

Field observations in NW Europe suggest that members of at least two fungus genera occur in woods and forested rock outcrops predominantly if not exclusively in such spots impregnated with elk urine: Byssonectria P.Karst. (syn. Inermisia Rifai; Eckblad 1968, Harmaja 1979 and 1986, Pfister 1994, Kullman 1998) and Pseudombrophila Boud. (syn. Nannfeldtiella Eckblad; Eckblad 1968, Harmaja 1979, Brummelen 1995). These genera belong to the order Pezizales (Ascomycetes) and they develop their macroscopic apothecia in the spring. Peziza Fr. may also include such species (see Harmaja 1986). In addition, a new species of green algae has been described from this habitat (Skuja 1943). Pfister (1995) mentioned the casual occurrence of cyanobacteria in connection with Byssonectria; however, it is not clear whether the urinated habitats are concerned.
Microfungi, too, seem to use these urinated habitats for nutrition: the present paper is the result of my repeated observations of conspicuous large, coloured chlamydospore-like conidia (aleuriospores) in the microscopic mounts made of dried specimens to study the Pseudombrophi$l a$ and Byssonectria species of this niche. The conidia were found to be born in mycelium growing on plant litter and mosses together with the mycelia and apothecia of the cup-fungi mentioned above; the fungus was found to be a member of Hyphomycetes (Deuteromycetes). Below, a species which is fairly constantly met with in this niche is described as Alciphila vulgaris Harmaja, the genus Alciphila Harmaja also being new. The microscopic mounts have been made of dried specimens collected in nature; the characters have been examined and measured in Melzer's reagent unless otherwise indicated.

\section{Alciphila Harmaja, n. gen.}

Deuteromycetes: Hyphomycetes. Mycelium superficiale. Hyphae crassae, hyalineae, septatae; septa sine fibulis; tunica crassa, inamyloidea, laevis. Conidia in cellula terminali hypharum nascentia, magna, ellipsoidea; basi truncato, cum poro centrali; tunica crassa, brunnea, cyanophiloidea, rimoso-ornamentata; perisporio hyalineo. Vernalis; habitat in silvis in locis urino alcis (Alces alces) saturatis, in societate Discomycetum; mycelium ad muscos non nec quisquilias emortuiis plantarum crescens. - Typus: Alciphila vulgaris Harmaja, n. sp.

Deuteromycetes: Hyphomycetes. Mycelium superficial, macroscopically discernible when dense, very pale brown, partly arranged into a net-like or rhizoid-like pattern (Fig. 1). Hyphae flexuous, cylindric, hyaline, septate, without clamps; wall thick, inamyloid, very weakly cyanophilic, smooth. Conidiophores absent; conidia developing terminally at hyphal ends within the ultimate cell; the penultimate cell in conidiogenous hyphae being conspicuously short. $\mathrm{Co}$ nidia chlamydospore-like, ca. 40-50 um long, ellipsoid, with a truncate base; wall proper thick, brown in water and Melzer's, cyanophilic, ornamented with coarse longitudinal ridges, the truncate basal wall having a central pore; the hyphal wall of the conidiogenous hypha (basal septum included) persisting in the ripe conidium as a tightly appressed perisporium. Colonies occur 


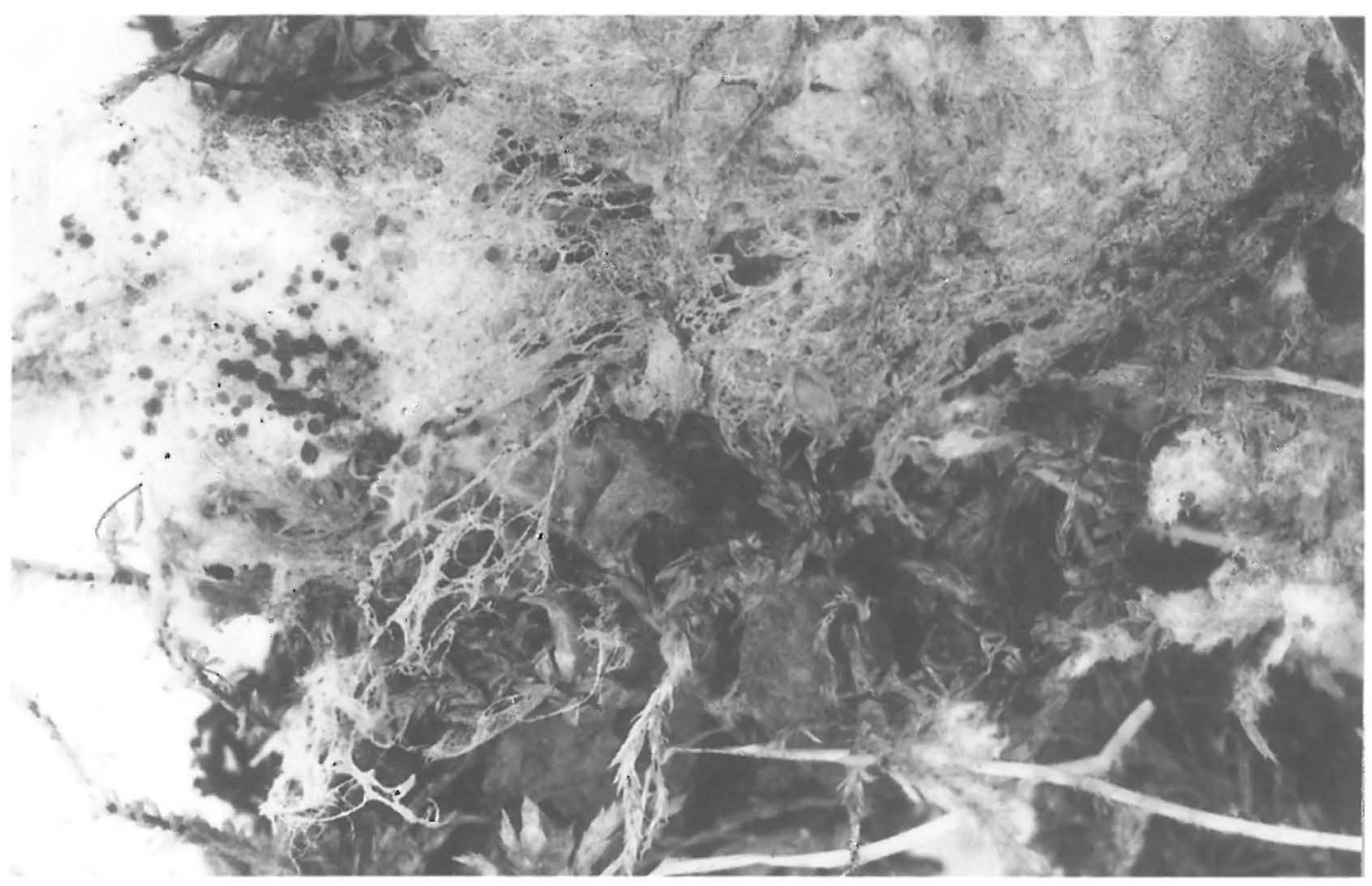

Fig. 1. Alciphila vulgaris, mycelium in dried collection $\times 2.7$ (type). - Photo Mauri Korhonen.

in spring on forest ground where an elk (Alces alces) has urinated; the mycelium grows on and among mosses, leaves, needles and other plant litter, being usually (always?) associated with the subicula (= mycelia) of Byssonectria spp. and Pseudombrophila spp.

\section{Alciphila vulgaris Harmaja, n. sp.}

Conidia (25-)40-50(-60) × (17-)25-38 $\mu \mathrm{m}$, ellipsoidea, brunnea, rimosa. - Holotypus: Finland, Etelä-Savo, Taipalsaari, Saikkola, S of Veteli. Stand of Pinus sylvestris saplings, accompanied by Byssonectria terrestris and Pseudombrophila tetraspora Harmaja, Grid $27^{\circ} \mathrm{E}$ 6789:556, 18.V.1974 Orvo Vitikainen $7790 b(\mathrm{H})$.

Hyphae rather interwoven, constricted at septa, $8-37 \mu \mathrm{m}$ in diameter, with a few oblique or rectangular branches; longitudinal walls ca. 0.6$2.5 \mu \mathrm{m}$ thick (in few places with internal swellings which may even reach across the lumen), fairly fragile, collapsed in places, composed of three layers of which the middle one being thickest and the inner one being refractive; the middle layer apparently being responsible for the weak cyan- ophily; septa of variable thickness, at times with a complex structure, a proportion of them possessing an outer, weakly to moderately cyanophilic external 'collar' (Fig. 2).

Conidia (25-)40-50(-60) ×(17-)25-38 um, ellipsoid with a broadly truncate (and very slightly eccentric) base. Contents of mature conidia, especially in Melzer's, with one very large central, spherical or elongated, oil drop, a few smaller ones, and additional granular matter. Wall proper thick (roughly $2.5 \mu \mathrm{m}$ in the long sides), appearing uniform without stratification, pale brown in water, melleous when young and pale to medium fulvous when mature in Melzer's, moderately to strongly cyanophilic throughout at all stages; a pore through the wall is present in the middle of the truncate base, with an external wall thickening surrounding the pore as a flat disc which is more strongly cyanophilic than the remainder of the wall. Surface of wall proper coarsely ornamented with ridges which are longitudinally oriented and of which (4-)8-12 being visible at a time with a magnification of $600 \times$; most of the ridges being unbranched; at the conidium base the proximal ends of the ridges are projecting 


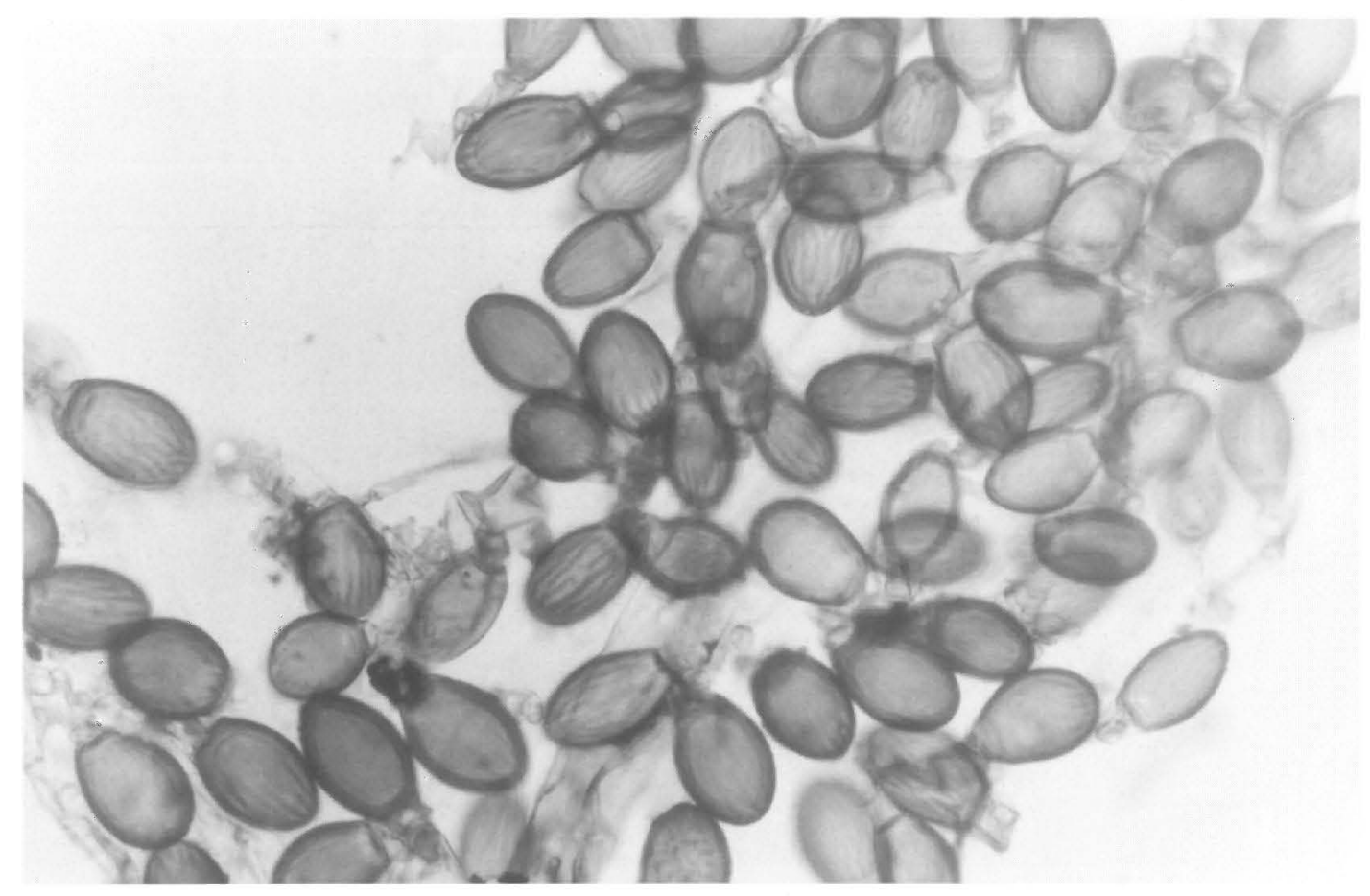

Fig. 2. Alciphila vulgaris, conidia in heated cotton blue $\times 270$ (type). - Photo Harri Harmaja.

slightly to form a 'crown' around the base. Perisporium thin, hyaline, inamyloid, weakly cyanophilic. Seemingly ripe conidia remain attached to their subtending hyphae for a long time; released conidia seen a few times (even the latter often carry an attached piece of the conidiogenous hypha as a 'tail'. (Figs 2-4)

Selected specimens examined: Finland. VarsinaisSuomi: Dragsfjärd, Galtarby, Tynglax, 23.IV.1981 Kvist (H); Kiikala, Lasisuo, Herakkaan lähde, 17.V.1970 Harmaja (H); Rymättylä, Raulahti, Välimäki, 29.IV.1979 Tuomikoski (H); Vihti, Vihtijärvi, Toivola, 13.V.1979 Tuomikoski (H). - Uusimaa: Inkoo, 12.V.1982 Harmaja \& Simojoki $(\mathrm{H})$; Siuntio, Flyt, Grid $27^{\circ} \mathrm{E}$ 6675:337, 3.IV.2002 Harmaja (H); Siuntio, Pikkala, 3.IV.2002 Harmaja (H). - Etelä-Karjala: Vehkalahti, Pyhältö, Ämmänmäki, 29.IV.1978 Fagerström (H). - EteläSavo: Taipalsaari, Saikkola (see type). Norway. Akershus: Nannestad, Tømte, 31.V.1970 Sivertsen \& Gulden $(\mathrm{H})$.

\section{Discussion}

Alciphila somewhat resembles the following form genera: Chlamydomyces Bainier, Lejosepium Sacc., Mycogone Link and Sepedonium
Link. Kiffer \& Morelet (2000) show this group of genera on the pages 80-83 (Table IV. A.: "Hyaline/Melanized Hyphales, Aleuriosporae"). Alciphila differs from these and any other genera of the Deuteromycetes in the complex structures of the walls of the hyphae and conidia, in the ornamentation of the conidium surface, and in the habitat ecology. Conidia are often discernible under a dissecting microscope as pale brown ellipsoid bodies.

Alciphila vulgaris either $(i)$ makes use of the elk urine, and thus simply shares the peculiar niche and the mode of nutrition with other organisms there or $(i i)$ is a parasite of other organisms: one or more species of Byssonectria would then appear the most probable host(s). The first alternative appears more plausible.

It is unclear where Alciphila should be placed in the fungal system. If a teleomorph is in existence, one could easily think of those representatives of the Pezizales (see the Introduction) which share the peculiar habitat: the most probable teleomorph would then be Byssonectria terrestris (Alb. \& Schwein.: Fr.) Pfister which is the commonest of such species. However, the hy- 


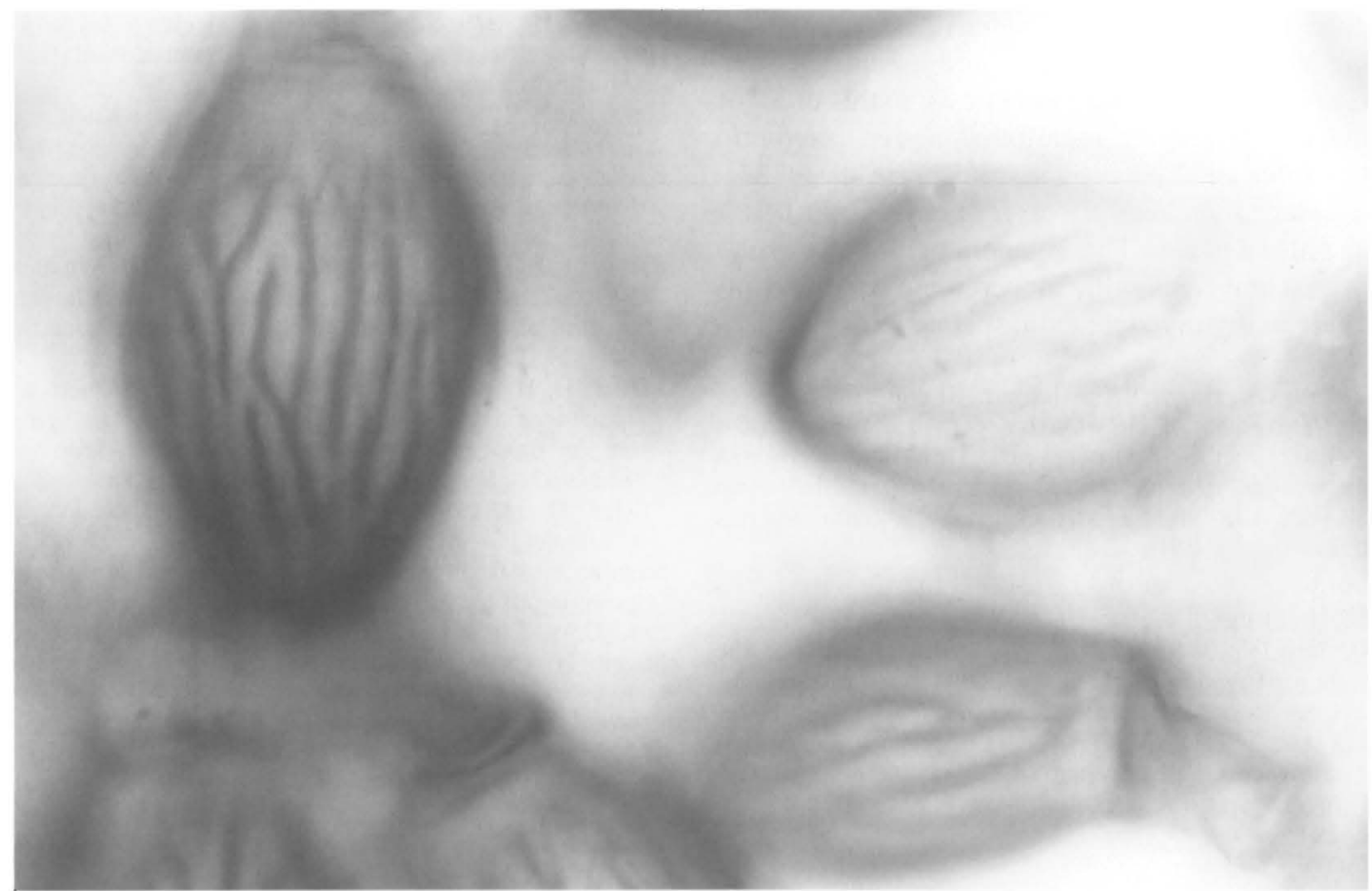

Fig. 3. Alciphila vulgaris, conidia in heated cotton blue $\times 1100$ (type). - Photo Harri Harmaja.

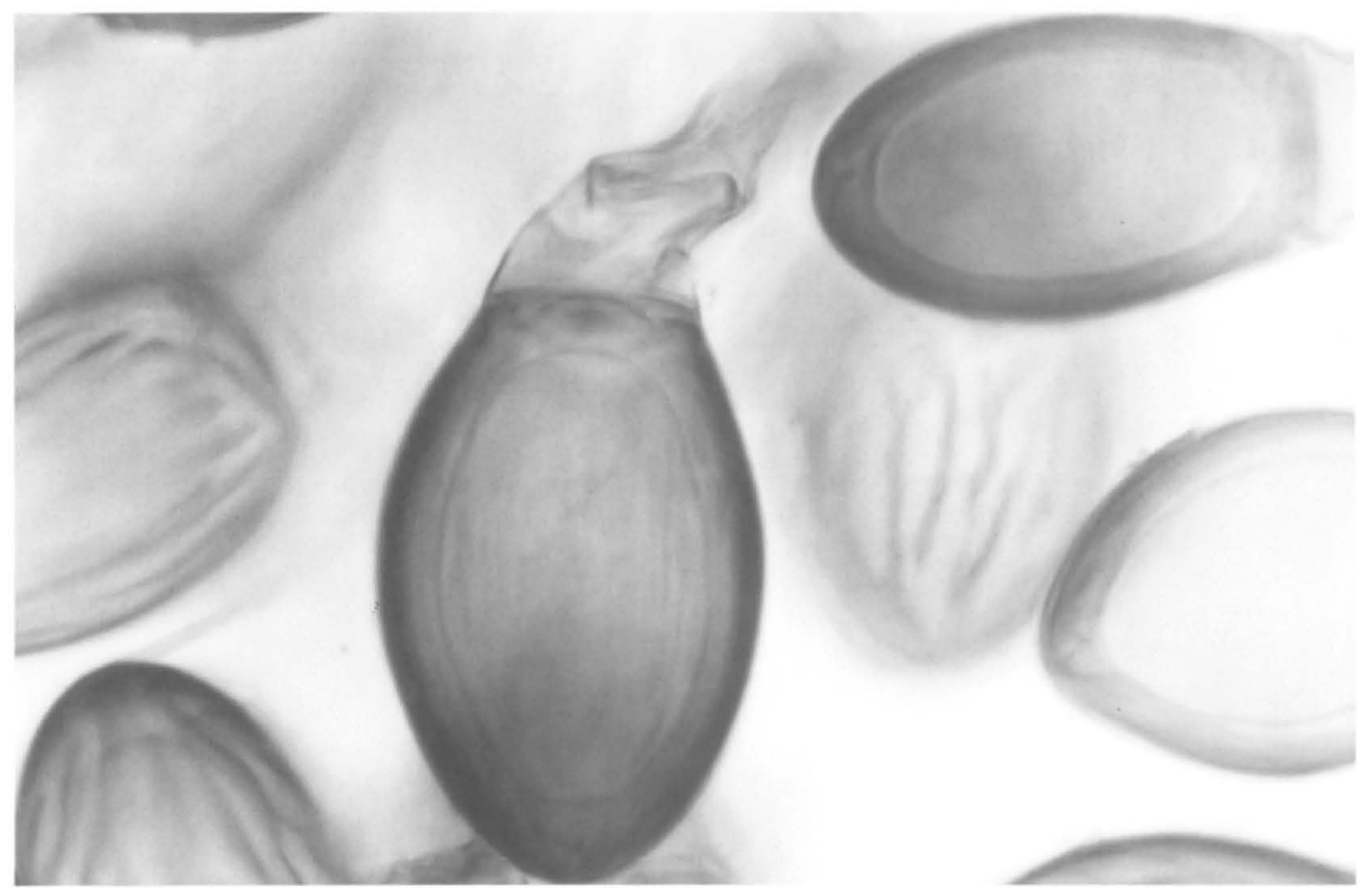

Fig. 4. Alciphila vulgaris, conidia in heated cotton blue $\times 1100$ (type). - Photo Harri Harmaja. 
phae of Alciphila, Byssonectria and Pseudombrophila are all dissimilar, and anamorphs that resemble Alciphila are not known in this order of the cup-fungi. As mentioned above, Alciphila has some similarity to the mitosporic states ( $M y$ cogone, Sepedonium) of Hypomyces (Fr.) Tul. and allied genera These genera belong to a group of Ascomycetes with inoperculate asci, and include many mycoparasitic species.

Acknowledgements: The Lammi Biological Station of the University of Helsinki has provided me excellent research facilities during years. Dr. Mauri Korhonen made a photograph for the present paper. Mr. Heino Vänskä, Lic. Phil., kindly checked the Latin descriptions.

\section{References}

Brummelen, J. van 1995: A world-monograph of the genus Pseudombrophila (Pezizales, Ascomycotina). Libri Bot. 14: 1-117.

Eckblad, F.-E. 1968: The genera of the operculate Discomycetes. A re-evaluation of their taxonomy, phylogeny and nomenclature. - Nytt Mag. Bot. 15: 1191.
Harmaja, H. 1979: Studies on vernal species of Gyromitra and Pseudombrophila (syn. Nannfeldtiella). Ann. Bot. Fennici 16: 159-162.

Harmaja, H. 1986: Studies on the Pezizales. - Karstenia 26: $41-48$.

Kiffer, E. \& Morelet, M. 2000: The Deuteromycetes. Mitosporic fungi. Classification and generic keys. - i$x i+273$ pp. Science Publishers Inc., Enfield.

Kullman, B. 1998: Two sibling species of the genus Byssonectria (Pezizales). Suppression of spore development under environmental stress. - Mycotaxon 69: 199207.

Pfister, D. H. 1994: A synopsis of the North American species of Byssonectria (Pezizales) with comments on the ontogeny of two species. - Mycologia 85: 952-962.

Pfister, D. H. 1995: A further note on Byssonectria (Pezizales). - Mycotaxon 53: 431-432.

Sagara, N. 1975: Ammonia fungi - a chemoecological grouping of terrestrial fungi. - Contr. Biol. Lab. Kyoto Univ. 24: 205-276, pls. 1-7.

Sagara, N., Okabe, H. \& Kikuchi, J. 1993: Occurrence of an agaric fungus Hebeloma on the underground nest of wood mouse. - Trans. Mycol. Soc. Japan 34: 315322.

Skuja, H. 1943: Ein Fall von fakultativer Symbiose zwischen operculatem Discomycet und einer Chlamydomonade. - Arch. Protistenk. 96: 365-376. 